\title{
Active targeting co-delivery system based on hollow mesoporous silica nanoparticles for antitumor therapy in ovarian cancer stem-like cells
}

\author{
$\mathrm{XIN} \mathrm{GUO}^{1 *}$, NAN GUO ${ }^{2 *}$, JIANWEN ZHAO ${ }^{1}$ and YUNLANG CAI ${ }^{3}$ \\ ${ }^{1}$ Medical School, Southeast University, Nanjing, Jiangsu 210009; ${ }^{2}$ Institute of Clinical Pharmacology, \\ Qilu Hospital of Shandong University, Jinan, Shandong 250012; ${ }^{3}$ Department of Gynaecology and Obstetrics, \\ Zhongda Hospital, Medical School, Southeast University, Nanjing, Jiangsu 210009, P.R. China
}

Received January 31, 2017; Accepted June 21, 2017

DOI: $10.3892 /$ or.2017.5829

\begin{abstract}
The combination of nanocarriers and chemotherapy drugs can release the chemotherapy drugs to the tumor tissue, which can enhance the antitumor effect and reduce the adverse reactions at the same time. In this study, a co-delivery system based on hollow mesoporous silica nanoparticles (HMSN) was developed and characterized. We also investigated the in vitro effect of this system on $\mathrm{CD} 117^{+} \mathrm{CD} 44^{+} \mathrm{A} 2780$ cell line. HMSN was selected as the nanocarrier, with - $\mathrm{COOH}$ modified on the surface and doxorubicin (DOX), NVP-AEW 541 (NVP) loaded inside. IGF-1R was chosen as the drug target, apoptosis rate and expression of cyclin B1, Bax, Bcl-xl, p-Akt were used to evaluate the antitumor effect of HMSN-COOH@DOX fluorescence NVP. The HMSN co-delivery system was successfully synthesized with encapsulation efficiency of 37\% (DOX) and 44\% (NVP), and high PH-sensitive property was observed. The apoptosis rate of $\mathrm{CD} 117^{+} \mathrm{CD} 44^{+} \mathrm{A} 2780$ ovarian cancer stem-like cells treated by HMSN co-delivery system were almost 3 times higher than those of the free drugs group. The expression of Bax was significantly increased while Bcl-xl, and p-Akt reduced $(\mathrm{P} \leq 0.05)$. These data indicate that the co-delivery system demonstrated a high efficiency in promoting apoptosis in ovarian cancer stem-like cells by targeting IGF-1R, but further study is still needed.
\end{abstract}

\section{Introduction}

Ovarian cancer represents the leading cause of deaths by women's malignancy in Western countries, without specific

Correspondence to: Professor Yunlang Cai, Department of Gynaecology and Obstetrics, Zhongda Hospital, Medical School, Southeast University, Nanjing, Jiangsu 210009, P.R. China

E-mail: zdyycyl@163.com

*Contributed equally

Key words: hollow mesoporous silica nanoparticles, ovarian cancer, IGF-1, NVP-AEW541, doxorubicin symptoms and reliable diagnosis in its early stage, ovarian cancer mortality reaches a high level of $70 \%$ in 5 years of diagnosis (1). The lack of effective treatment for recurrent cases contributes to the problem. One big challenge is the development of resistance in as many as $60 \%$ patients treated with conventional chemotherapy drugs. In recent years, the molecular targeting therapy applying gefitinib and bevacizumab has shown potential, although the heterogeneous response by different patients continues to be a major obstacle for its clinical application (2). The development of new targeting modalities is essential for the improvement on the management of recurrent/drug-resistant ovarian cancer patients.

Since 2001, novel nanomaterials have attracted attention of biomedical investigators. The coupling of chemotherapy drugs with nanocarriers opened a new avenue in cancer therapy (3). Based on the physiological characteristics of tumor tissue, nanocarriers can be designed to reduce the toxicity and drug resistance (4). The ideal nanocarriers can protect the activities of drugs, prolong the plasma half-life, and selective releasing of drug in the tumor tissue. The suitable particle size capable of achieving the enhanced permeability and retention (EPR) is the foundation of the targeting therapy by nanocarriers (5). Drug release is controlled by a switch, which is usually an environment condition such as temperature, $\mathrm{pH}$ and magnetic (6). Specific chemical groups, such as folate receptor, monoclonal antibodies, nucleic acid and polypeptide, was used as targeting ligands to modify the nanocarriers to promote their cellular uptake. The high abundance of receptors on cancer cell membrane may specifically enhance the accumulation of the drug in cancer cells.

In this study the hollow mesoporous silica nanoparticles (HMSN) were chosen as the nanocarriers due to their larger aperture, good histocompatibility, stable chemical property and suitable diameter $(50 \mathrm{~nm})(4)$. $\mathrm{pH}$ value was chosen as the switch. The $\mathrm{pH}$ of the blood circulation system is between 7.35 and 7.45 , whereas the $\mathrm{pH}$ will decrease to 6.0-6.5 in the tumor tissues and further reduce to 4.0-6.0 in tumor cells (7). This can change the interaction between HMSN and drugs from electrostatic attraction to electrostatic repulsion. NVP-AEW541 (NVP) is a small molecule inhibitor of insulin-like growth factor receptor (IGF-1R). NVP was the 
targeting ligands that are modified on HMSN. Insulin-like growth factor (IGF) pathway is involved in the regulation of cancer stem cells and associated with the progression of ovarian cancer (8-10). Thus, HMSN modified with NVP tend to internalized into cancer cells via the specific recognition. Doxorubicin (DOX) is one of the most widely used anticancer drugs for various treatment of tumor. Due to the red fluorescence of emission DOX, the localization of nanocarriers can be clearly observed in tumor cells.

In this study, the enhancement on the uptake of HMSN-COOH@DOX fluorescence NVP particle by ovarian cancer stem cells was determined. Moreover, we examined whether the co-delivery of NVP and DOX could achieve a synergism in the killing of cancer cells. These studies on the new targeting methods have a clear basic science and clinical significance.

\section{Materials and methods}

$C D 117^{+} \mathrm{CD} 44^{+} \mathrm{A} 2780$ cell culture. The $\mathrm{CD} 117^{+} \mathrm{CD} 44^{+} \mathrm{A} 2780$ cell line, were all obtained from KeyGen Co., Ltd. (Nanjing, Jiangsu, China). This cell line displayed the characters of cancer stem cells $(11,12)$. Cells were cultured in serum-free medium at $37^{\circ} \mathrm{C}$ in a $5 \% \mathrm{CO}_{2}$ atmosphere.

Main reagents and drugs. Insulin like growth factor I (IGF-1), mouse monoclonal antibody against IGF-1, IGF-2 and IGF-1R, and fluorescent NVP, DOX were obtained from KeyGen Co., Ltd. The HMSN and N-[(3-trimethoxysily)prop] ethylenediamine triacetic acid trisodium salt were kindly donated by the Department of Clinical Laboratory, School of Medicine, Southeast University, Nanjing.

Immunohistochemical analysis. The $\mathrm{CD} 117^{+} \mathrm{CD} 44^{+} \mathrm{A} 2780$ cells were cultured in complete medium overnight. The medium was replaced with serum-free medium and culture continued for $48 \mathrm{~h}$. Immunohistochemistry was performed as previously published $(13,14)$. Briefly, cells were fixed with methanol and cultured with primary antibody (diluted at 1:200) overnight at $4^{\circ} \mathrm{C}$ and followed by secondary antibody for $2 \mathrm{~h}$ at room temperature. Color development was carried out with diaminobenzidine and cells were counterstained with hematoxylin. The expression of IGF-1, IGF-2 and IGF-1R in cells was examined under an optical microscope.

Determination of the optimal concentration of IGF-1. Cells were cultured in complete medium overnight, the medium was replaced by serum-free medium. After $12 \mathrm{~h}, 200 \mu \mathrm{l}$ of IGF-1 solutions with different concentrations (10, 25, 40 and $55 \mathrm{ng} / \mathrm{ml}$ ) was added, respectively. The number of cells was counted after $24 \mathrm{~h}$, and the optimal IGF-1 concentration inducing the strongest proliferation was used for subsequent experiments.

Determining the role of IGF-1R and NVP in cell cycle regulation and apoptosis. The experiments were performed with three groups, the IGF-1 stimulation group, the NVP $(10 \mu \mathrm{M})$-inhibition group and control group. Cells were seeded in 6-well plates $\left(5 \times 10^{5}\right)$, serum-starved for $24 \mathrm{~h}$, and exposed to IGF-1 or NVP for $24 \mathrm{~h}$. Following treatment, cells were stained with $50 \mu \mathrm{g} / \mathrm{ml}$ propidium iodide and $30 \mu \mathrm{g} / \mathrm{ml}$ RNase A in 1X PBS. The percentage of cells in specific cell cycle phases was determined with a flow cytometer equipped with a 488-nm argon laser (BD Biosciences, San Jose, CA, USA). Annexin V-FITC apoptosis detection kit (BD Biosciences) was used to detect cell apoptosis according to the manufacturer's instructions. To detect the expression of cyclin B1, the rabbit polyclonal antibodies raised against cyclin B1 (Boster, Wuhan, Hubei, China) was applied for 12 h. Following extensive washing, samples were incubated with HRP labeled goat anti-rabbit IgG for $1 \mathrm{~h}$, before color development with chemiluminescence kit (Boster).

Synthesis of HMSN-COOH@DOX fluorescence NVP co-delivery system. N-[(3-trimethoxysily)propy]ethylenediamine triacetic acid trisodium $(100 \mu \mathrm{l})$, which was chosen as the donator of carboxyl, was dissolved in $10 \mathrm{ml}$ anhydrous ethanol, and HMSN (10 mg) were added and the mixture was incubated at $80^{\circ} \mathrm{C}$ for $24 \mathrm{~h}$. Finally, the modified HMSN (HMSN-COOH) were collected by centrifugation and rinsed with ethanol and deionized water. DOX (2 mg) was dissolved in $10 \mathrm{ml}$ PBS (pH 7.4), and $10 \mathrm{mg} \mathrm{HMSN-COOH}$ was added and the mixture was stirred for $24 \mathrm{~h}$ at room temperature. HMSN-COOH@DOX and supernatant were, respectively collected by centrifugation. Fluorescence NVP $(0.5 \mathrm{mg})$ was suspended in $10 \mathrm{ml}$ PBS (pH 8.0) and subsequently mixed with 10 mg of HMSN-COOH@DOX. Following continued stirring for $24 \mathrm{~h}$, the HMSN-COOH@DOX fluorescence NVP was collected by centrifugation, and resuspended in $10 \mathrm{ml}$ PBS and stored in $4^{\circ} \mathrm{C}$.

Determining the entrapment efficiency and loading efficiency of DOX and fluorescence NVP.10 mg of DOX was dissolved in $10 \mathrm{ml}$ PBS ( $\mathrm{pH} \mathrm{7.4)}$ to obtain the stock solution $(1 \mathrm{mg} / \mathrm{ml}$ ). Serial dilution was performed with PBS to obtain solutions with concentrations of 500, 400, 300, 200, 100, 50 and $25 \mu \mathrm{g} / \mathrm{ml}$. Infrared absorption of DOX was measured by UV spectrophotometer at $480 \mathrm{~nm}$, and the calibration curve of absorbance (Y) and concentration (X) was constructed by linear regression. The following formula was used to calculate the entrapment efficiency and loading efficiency: loading efficiency $(\%)=$ final loaded DOX/total quality (drug and nanocarrier) x 100; entrapment efficiency $(\%)=$ final loaded DOX/initial feed DOX x 100.

Stock solution of fluorescence NVP $(0.5 \mathrm{mg} / \mathrm{ml})$ was prepared and diluted to 100, 80, 60, 40, 20 and $10 \mu \mathrm{g} / \mathrm{ml}$ with DMSO. The absorbance of fluorescence NVP was measured with UV spectrophotometer at $260 \mathrm{~nm}$. The absorbance (Y) and the fluorescence NVP (X) were used to obtain the calibration curve.HMSN-COOH@DOX fluorescence NVP (1 mg) was dispersed in $5 \mathrm{ml}$ DMSO. Then the loading rate and encapsulation rate were calculated by the following formula: loading efficiency $(\%)=$ final loaded fluorescence NVP/total quality (drug and nanocarrier) x 100; entrapment efficiency $(\%)=$ final loaded fluorescence NVP/initial feed NVP x 100.

The release rate of $D O X$ and fluorescence NVP at different $p H$.HMSN-COOH@DOX fluorescence NVP (1 mg) was resuspended in $10 \mathrm{ml} \mathrm{PBS}$ at $\mathrm{pH} 7.4,6.5,5.5$ and 4.5 
A

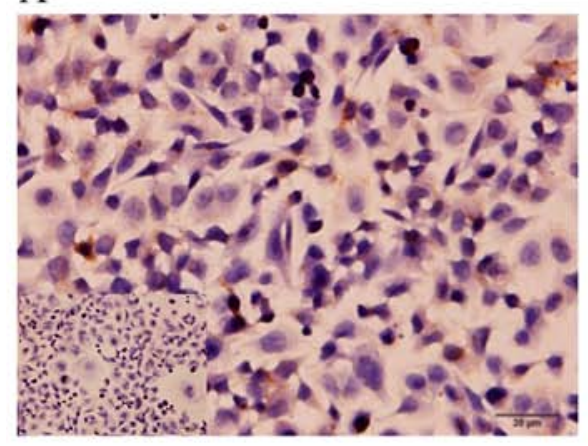

B

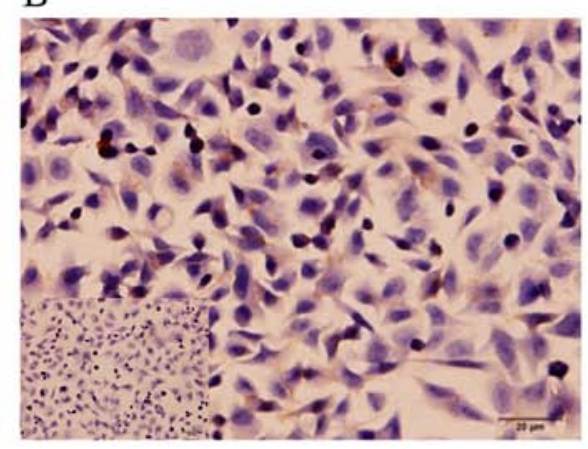

$\mathrm{C}$

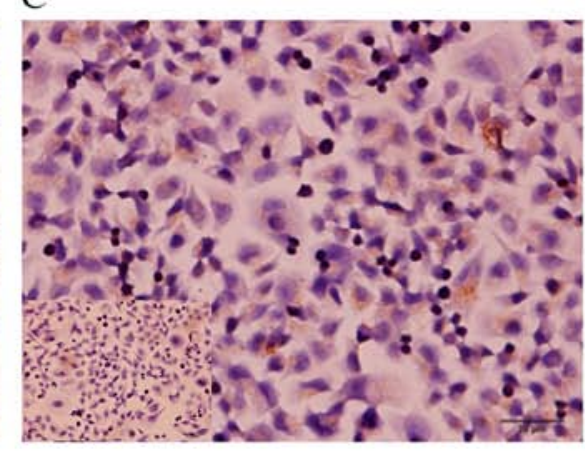

Figure 1. The IGF-1 (A), IGF-2 (B), IGF-1R (C) are highly expressed on the cell membrane and in the cytoplasm of CD117+CD44+A2780 cell line (negative control is shown in the lower left corner of each graph).

respectively. The OD values of each group were measured every $20 \mathrm{~h}$ for $120 \mathrm{~h}$. The experiment was repeated three times to calculate the mean DOX-release rate.HMSN-COOH@ DOX fluorescence NVP $(1 \mathrm{mg})$ was resuspended in PBS at $\mathrm{pH}$ 7.4, 6.5 and 5.5, and OD values were measured every $10 \mathrm{~h}$ for $80 \mathrm{~h}$. The experiment was repeated three times to calculate the mean fluorescence NVP-release rate.

Detection of the $\zeta$-potential of nanocarriers at different $\mathrm{pH}$. The carboxylic group modified on the surface of HMSN was detected by infrared spectrometer (Shimadzu, Japan). The form and size of HMSN drug delivery system ware observed by transmission electron microscopy (TEM) and scanning electron microscopy (SEM) (Hitachi, Japan). The $\zeta$-potential of HMSN and HMSN-COOH in different $\mathrm{pH}$ environment was detected by dynamic light scattering (MAL1043118, Malvern Instruments Ltd.).

In vitro effect of HMSN-COOH@DOX fluorescence NVP co-delivery system. Intracellular accumulation, apoptosis ratio, inhibition rate and protein level of Bax, $\mathrm{Bcl}-\mathrm{xl}$ and $\mathrm{p}-\mathrm{Akt}$ were used as the indexes to determine the in vitro effects of this system. Cells were plated in petri dish at a density of $5 \times 10^{5}$ per well. HMSN-COOH@DOX fluorescence NVP (1 mg) or HMSN-COOH@DOX was resuspended in $1 \mathrm{ml}$ PBS, and $200 \mu \mathrm{l}$ was applied to each well. Equivalent amount of free DOX and fluorescence NVP were added to control groups. Medium was removed at one, two and three hours, the intracellular accumulation of HMSN-COOH@DOX fluorescence NVP was observed by using laser confocal microscopy. Cells were collected to detect the apoptosis ratio with the methods described above.

Three groups, HMSN-COOH@DOX fluorescence NVP, HMSN-COOH@DOX and free DOX NVP group, were used to examine the inhibition rate. Cells were inoculated to 96 -well culture plates at a density of 5,000 cells per well, cultured for $24 \mathrm{~h}$ with complete medium, before drugs were added to each group as described above. After $8 \mathrm{~h}, 10 \mu \mathrm{l}$ of MTT $(5 \mathrm{mg} / \mathrm{ml})$ was added to each well and incubation was continued for $4 \mathrm{~h}$ at $37^{\circ} \mathrm{C}$. DMSO $(100 \mu \mathrm{l})$ was added to each well to dissolve the crystalline formazan after removing MTT solution. The absorbance of each well was detected on microplate reader (Enspire Instruments, Perkin-Elmer, USA) at a wavelength of $490 \mathrm{~nm}$.

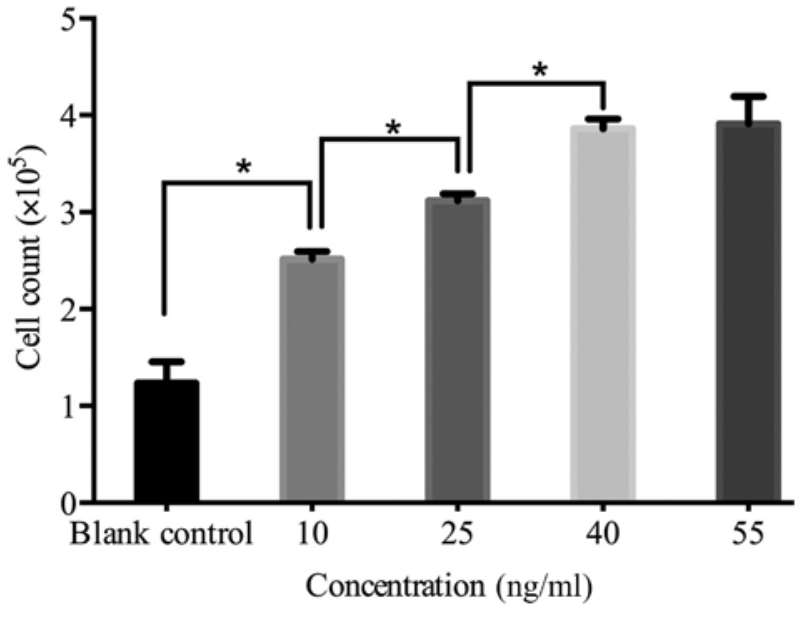

Figure 2. The proliferation of $\mathrm{CD} 117^{+} \mathrm{CD} 44^{+} \mathrm{A} 2780$ cells was increased by IGF-1 concentration-dependently. Cell count was used as the proliferation index. The optimal concentration chosen and applied in later experiments was $40 \mathrm{ng} / \mathrm{ml}$. Significant differences, ${ }^{*} \mathrm{P} \leq 0.05$.

The expression of Bax, Bcl-xl and p-Akt in experimental and control groups were detected by western blotting. Rabbit polyclonal antibodies raised against p-Akt, Bax and Bcl-xl (Boster) were used as the primary antibodies cultured with cells for $12 \mathrm{~h}$. Following extensive washing, samples were incubated with HRP labeled goat anti-rabbit IgG for $1 \mathrm{~h}$, before color development with chemiluminescence kit (Boster).

\section{Results}

Immunohistochemical analysis. The expression of IGF-1, IGF-2 and IGF-1R in CD117 ${ }^{+} \mathrm{CD} 44^{+} \mathrm{A} 2780$ cells was examined with the use of immunohistochemistry. The expression of these proteins, as indicated by the brown staining, was detected in cell membrane and cytoplasm (Fig. 1). The result demonstrated that this cell line expresses high levels of ligands and receptors of the IGF pathway. Therefore, these cells can be used in this experiment.

The optimal concentration of IGF-1. Our results showed that even at a relatively low concentration IGF-1 can effectively stimulate cell proliferation, and the effect is time- and concentration-dependent. As shown in Fig. 2, the proliferation 
A

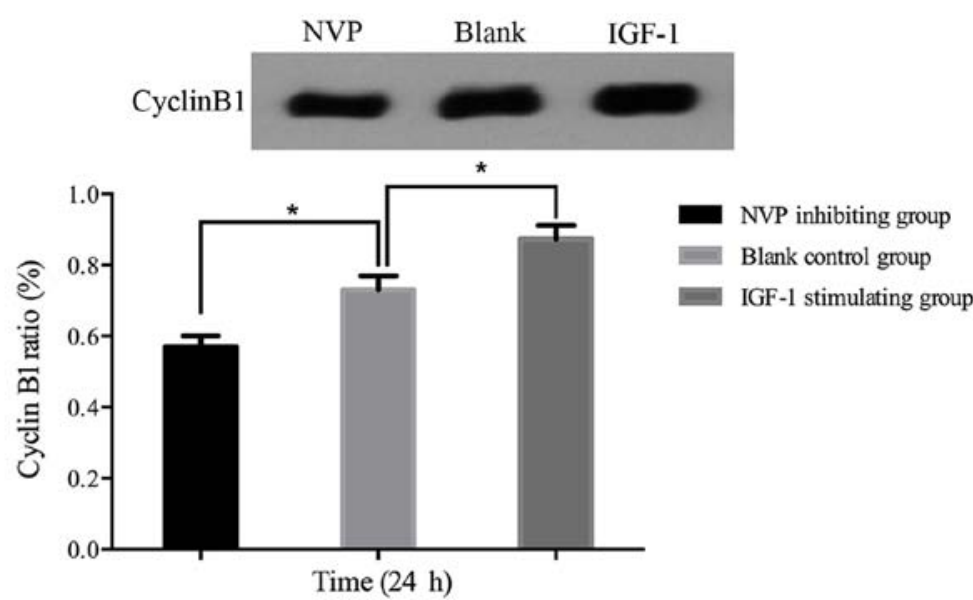

B

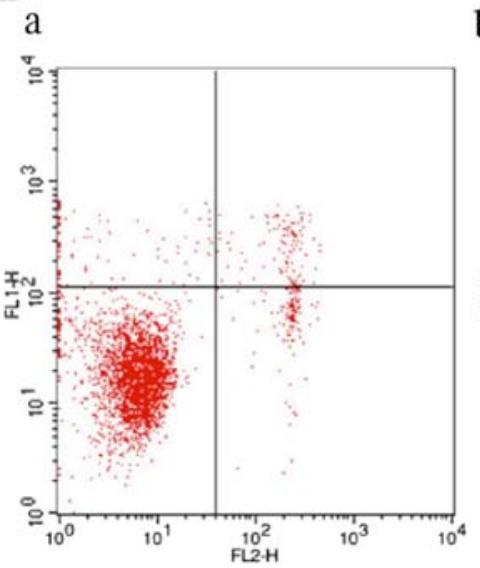

b

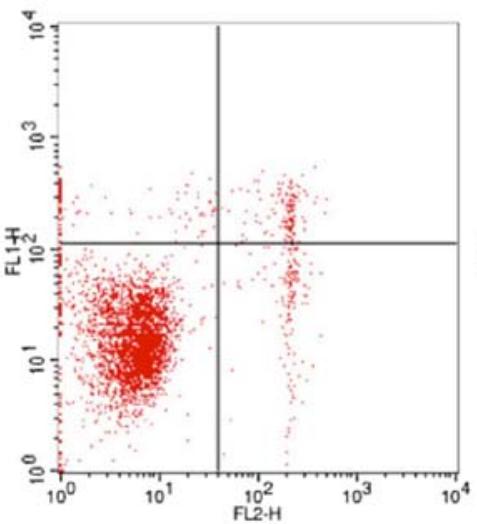

c

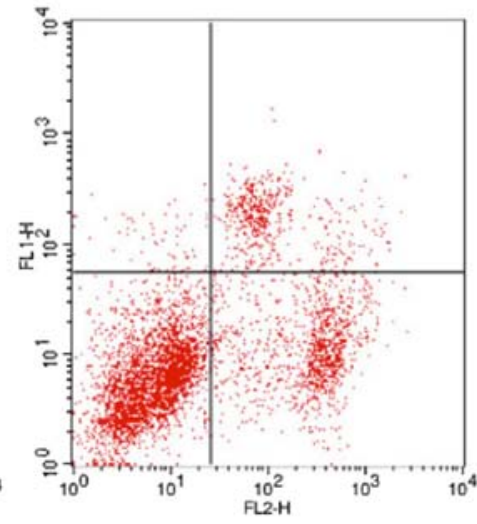

Figure 3. Effect of IGF-1 on cell apoptosis. Cyclin B1 was highly expressed in IGF-1 stimulating group (A). The apoptosis rate in the NVP inhibiting group $(32.79 \pm 0.34 \%)$ assayed by FCM was significantly higher than that of IGF-1 stimulating group $(6.53 \pm 0.36 \%)$ and control $(8.38 \pm 0.25 \%)$ groups $[(B)$ a, control; b, IGF-1 $40 \mathrm{ng} / \mathrm{ml} ; \mathrm{c}, \mathrm{NVP} 10 \mu \mathrm{M} / \mathrm{ml}$.

was enhanced with the increasing concentration of IGF-1. At concentrations $>40 \mathrm{ng} / \mathrm{ml}$ no further increase in cell proliferation was observed. The optimal concentration chosen and applied in later experiments was $40 \mathrm{ng} / \mathrm{ml}$.

IGF-1 and NVP affect cell cycle regulation and apoptosis. To examine the effects of IGF-1 and IGF-1R inhibitor on cell cycle and cell apoptosis, cancer cells were divided into IGF-1 stimulating group, NVP inhibiting group and control group. When compared with the control group, the cells in S phase were significantly increased $(\mathrm{P} \leq 0.05)$, whereas relatively percentages of G1 and G2 phases were significantly decreased in the IGF-1 stimulating group $(\mathrm{P} \leq 0.05)$. The NVP inhibiting group displayed an accumulation of cells in $\mathrm{G} 2$ phase and reduction of percentages in G1 phase and S phases $(\mathrm{P} \leq 0.05)$ (Table I).

The expression of cyclin B1 was consistent with the cell cycle distribution. Cyclin B1 was significantly higher in IGF-1 stimulating group $(\mathrm{P} \leq 0.05)$, while in NVP inhibiting group it was lower than that in other groups $(\mathrm{P} \leq 0.05)$ (Fig. 3). Therefore, IGF-1 can promote ovarian cancer stem cell proliferation by activating IGF-1R, and NVP can block this effect.

As expected, the apoptosis rate in the NVP inhibiting group $(32.79 \pm 0.34 \%)$ was significantly increased when compared to the IGF-1 stimulating $(6.53 \pm 0.36 \%)$ and control $(8.38 \pm 0.25 \%)$ groups $(\mathrm{P} \leq 0.05)$ (Fig. 3). Thus, IGF-1R is a potential target
Table I. The cell cycle distribution of $\mathrm{CD} 117^{+} \mathrm{CD} 44^{+} \mathrm{A} 2780$.

\begin{tabular}{lccc}
\hline & \multicolumn{3}{c}{ Cell count $(\%)$} \\
\cline { 2 - 4 } Group & G1 phase & S phase & G2 phase \\
\hline IGF-1 & $36.1 \pm 1.30^{\mathrm{a}}$ & $56.5 \pm 1.45^{\mathrm{a}}$ & $7.30 \pm 0.55^{\mathrm{a}}$ \\
NVP & $49.0 \pm 0.70^{\mathrm{a}}$ & $40.6 \pm 0.65^{\mathrm{a}}$ & $10.3 \pm 0.37^{\mathrm{a}}$ \\
Control & $52.4 \pm 0.37$ & $37.8 \pm 0.56$ & $9.67 \pm 0.63$
\end{tabular}

${ }^{a} \mathrm{P} \leq 0.05$, compared with the blank control group.

for cancer stem-like cells, and inhibition of IGF-1R led to cell apoptosis.

Characterization of HMSN-COOH@DOX fluorescence NVP co-delivery system. The HMSN and - $\mathrm{COOH}$ were characterized by IR: a spectral peak at $400-1,400 \mathrm{~cm}^{-1}$ was mainly silicon oxygen tetrahedron frame; the wide and strong absorption peak at $1,104 \mathrm{~cm}^{-1}$ was $\mathrm{Si}-\mathrm{O}-\mathrm{Si}$ asymmetric stretching vibration peak; the amino vibration absorption peak was at $3,430 \mathrm{~cm}^{-1}$. Besides the characteristics of HMSN, the special absorption peak of carboxylic can be clearly demonstrated in the spectrum: the asymmetric and symmetric stretching vibration 
A

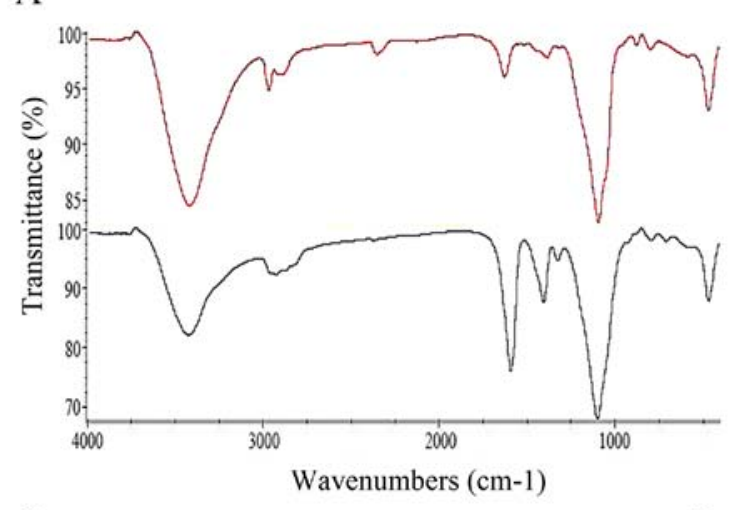

$\mathrm{C}$

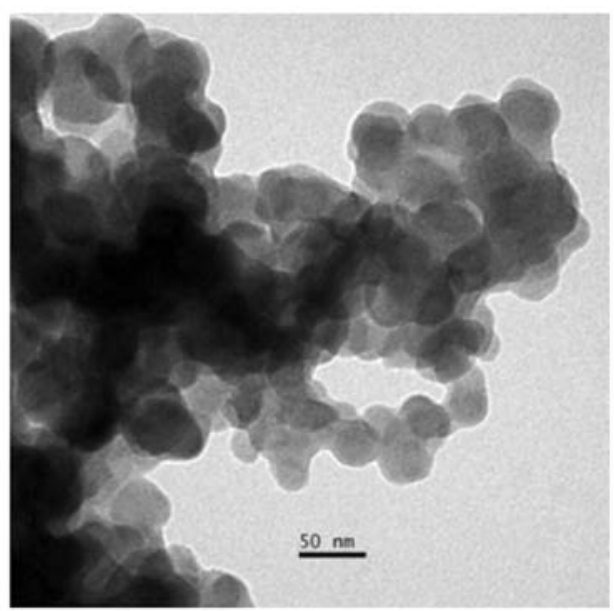

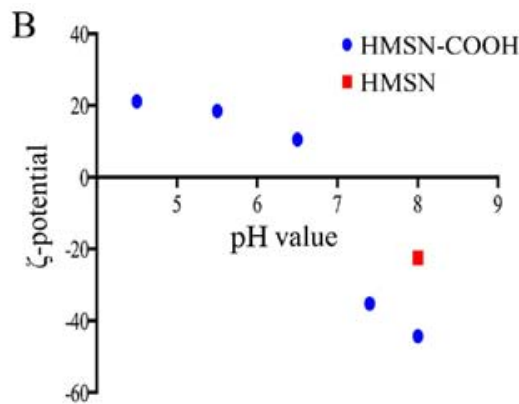

$\mathrm{D}$

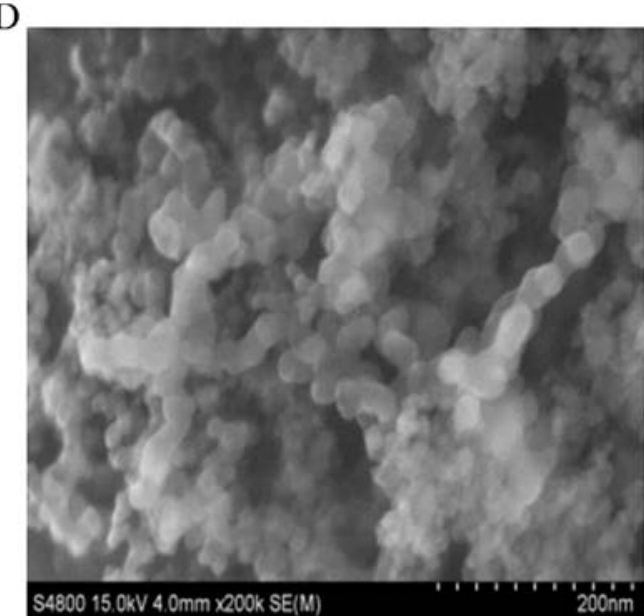

Figure 4. Characterization of the HMSN-COOH@DOX fluorescence NVP. (A) The IR analysis of HMSN and HMSN-COOH. (B) $\zeta$-potential of HMSN-COOH in PBS, the negative charge of HMSN was increased after - $\mathrm{COOH}$ loaded and changed into positive charge with the decrease of $\mathrm{pH}$ value; TEM images [(C) x20,000 times] and SEM images [(D) x20,000 times] of co-delivery system indicated the size and form of HMSN were not changed after drug loaded.
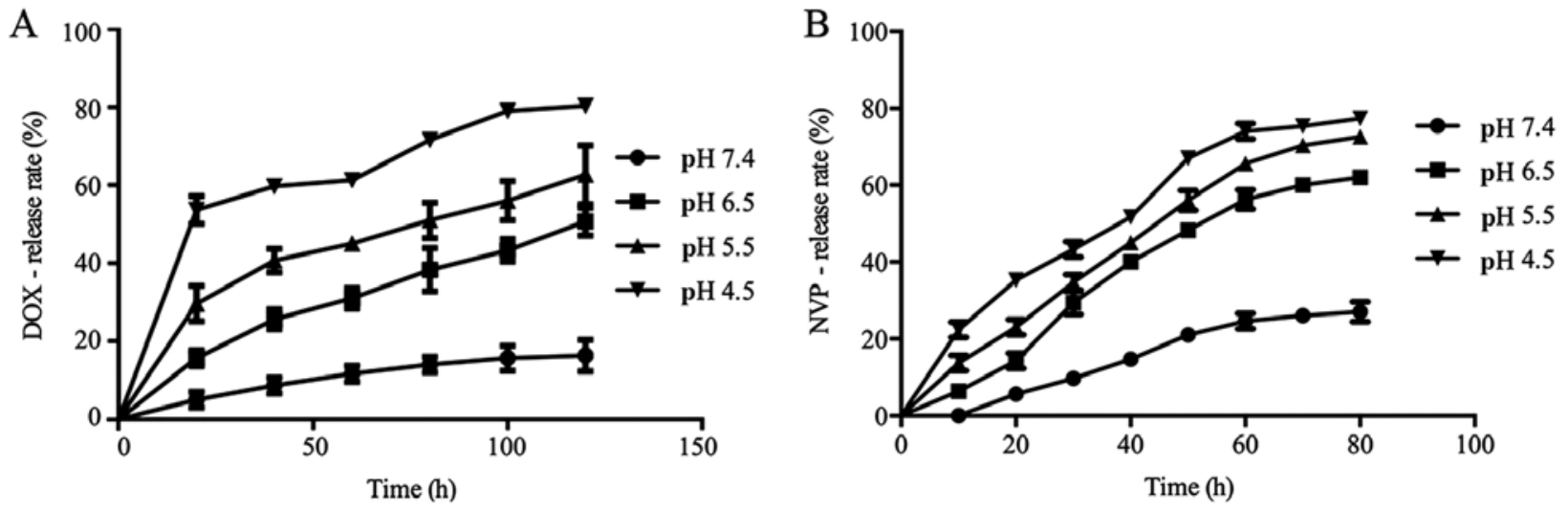

Figure 5. The release rates of DOX (A) and NVP (B) both accelerated in pace with the decline of $\mathrm{pH}$ value.

peak at $1,596 \mathrm{~cm}^{-1}$ and $1,412 \mathrm{~cm}^{-1}(15)$ confirm the carboxylic acid was modified on the surface of HMSN (Fig. 4).

The result of SEM and TEM imaging showed that the size and form of HMSN were not changed after drug loading. However, the negative charge was increased after modification of carboxyl group on the surface of HMSN, which could be beneficial to drug loading by electrostatic attraction. The carboxyl group was protonated and the electrostatic attraction of DOX was weakened along with the gradually reduced $\mathrm{pH}$.
As a result, the release rate of drugs was increased (Fig. 4). Thus, the modification on the surface of HMSN provided a platform for the control of drug loading and release through changes of the electrostatic charge.

The loading quantity, encapsulation efficiency and release rate of drugs. There is a linear relationship between OD value and the concentration of DOX. The calibration curve is $\mathrm{Y}=0.032 \times \mathrm{X}+0.071\left(\mathrm{R}^{2}=0.998\right)$, where $\mathrm{Y}$ represents the OD 
A a

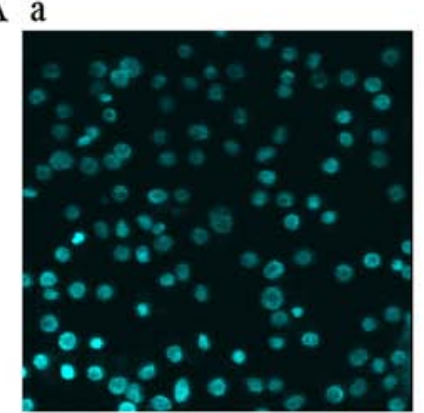

B a

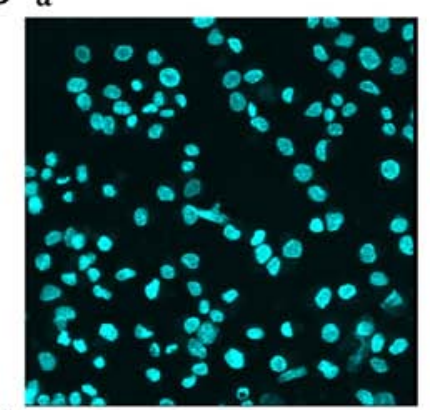

C a

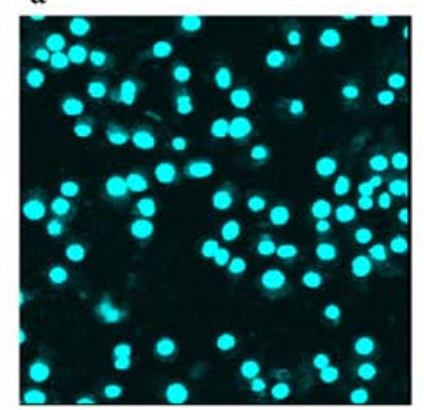

b

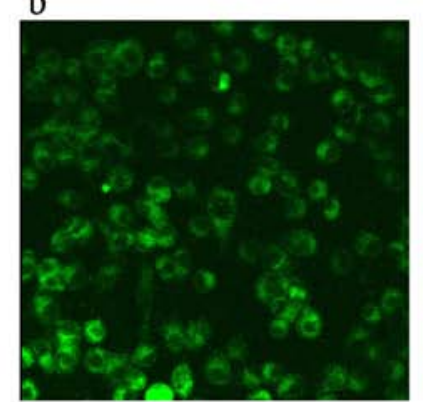

b

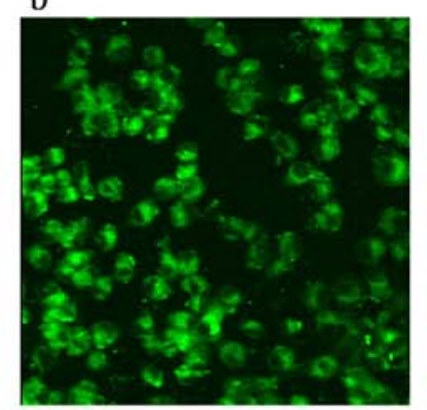

b

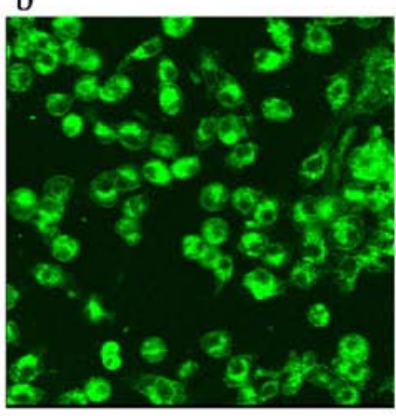

c

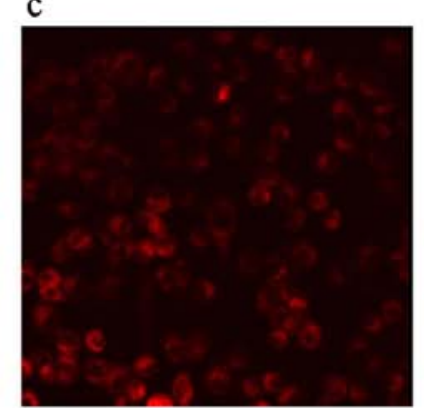

c

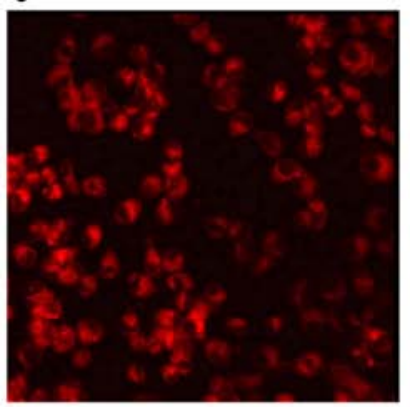

c

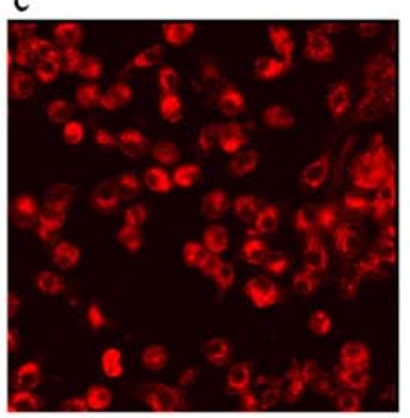

$\mathrm{d}$

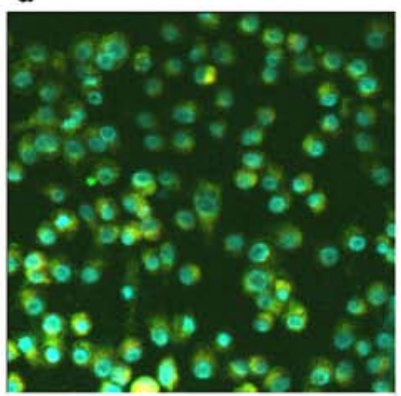

d

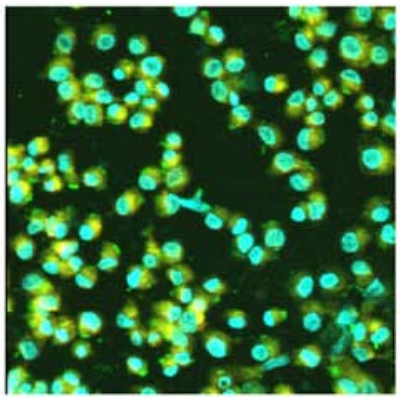

d

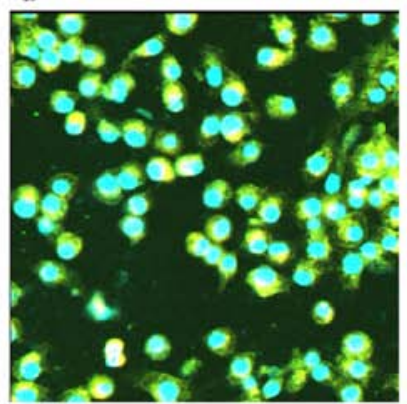

Figure 6. Microscopic imaging of $\mathrm{CD} 117^{+} \mathrm{CD} 44^{+} \mathrm{A} 2780$ cells after incubated with HMSN@DOX fluorescence NVP for $1 \mathrm{~h}(\mathrm{~A}), 2 \mathrm{~h}(\mathrm{~B})$ and $3 \mathrm{~h}(\mathrm{C})$ at $37^{\circ} \mathrm{C}$ (a, Hoechst 33342 fluorescence; b, DOX fluorescence; c, NVP green fluorescence; d, overlapping). The co-delivery system gradually gathered intracellularly and penetrated into nucleus over time.

value and $\mathrm{X}$ represents concentration. According to the formula described above, the DOX-encapsulation efficiency was $37 \%$, and loading quantity was $6.17 \%$. In alkaline environment DOX almost did not release, when the $\mathrm{pH}$ decreases to $<7.4$, the release significantly accelerated $(\mathrm{P} \leq 0.05)$. Similarly, the calibration curve of fluorescence NVP was $\mathrm{Y}=0.0681 \times \mathrm{X}$ $\left(\mathrm{R}^{2}=0.991\right)$, where $\mathrm{Y}$ represents the OD value and $\mathrm{X}$ represents concentration. The encapsulation efficiency was $44 \%$, and the loading quantity was $2.10 \%$. When $\mathrm{pH}$ was at 6.5 or 5.5 , the release rates of fluorescence NVP were significantly higher than that at $\mathrm{pH} 7.4(\mathrm{P} \leq 0.05)$ (Fig. 5). Therefore, we successfully synthesized a NVP-modified and $\mathrm{pH}$-sensitive co-delivery system.

Efficiency of the HMSN-COOH@DOX fluorescence NVP co-delivery system. HMSN@DOX fluorescence NVP co-delivery system can be gradually gathered in the intracellular, and penetrated into the nucleus with extension of time (Fig. 6). Cell apoptosis was significantly increased in the HMSN-COOH@DOX fluorescence NVP group than that of HMSN-COOH@DOX group $(\mathrm{P} \leq 0.05)$. NVP combined with DOX can achieve more efficient cell killing. Compared with the control group, DOX and NVP loaded in the HMSN had stronger apoptotic effect $(\mathrm{P} \leq 0.05)$ (Fig. 7). Similarly, the cell growth inhibition rate of HMSN-COOH@DOX fluorescence NVP group was higher than that of the other two groups

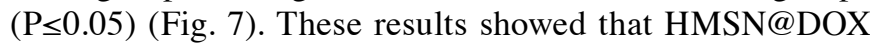
fluorescence NVP co-delivery system could be potentially applied for cancer therapy.

The expression of Bax was significantly increased in HMSN-COOH@DOX fluorescence NVP group ( $\mathrm{P} \leq 0.05)$, while the expression of Bcl-xl and p-Akt were significantly decreased $(\mathrm{P} \leq 0.05)$ (Fig. 7). The results showed that the proliferation and apoptosis of $\mathrm{CD} 117^{+} \mathrm{CD} 44^{+} \mathrm{A} 2780$ cells were regulated by PI3K/AKT pathway, which can be suppressed by NVP.

\section{Discussion}

Tumor recurrence represents a serious challenge for cancer therapy. For primary ovarian cancer patients who have received cytoreductive surgery and platinum-based combination chemotherapy, a long period of complete remission is expected. However, almost $70 \%$ of patients will experience recurrence (1). According to previous studies, the proliferation of cancer stem cells directly contribute to tumor recurrence. 
A
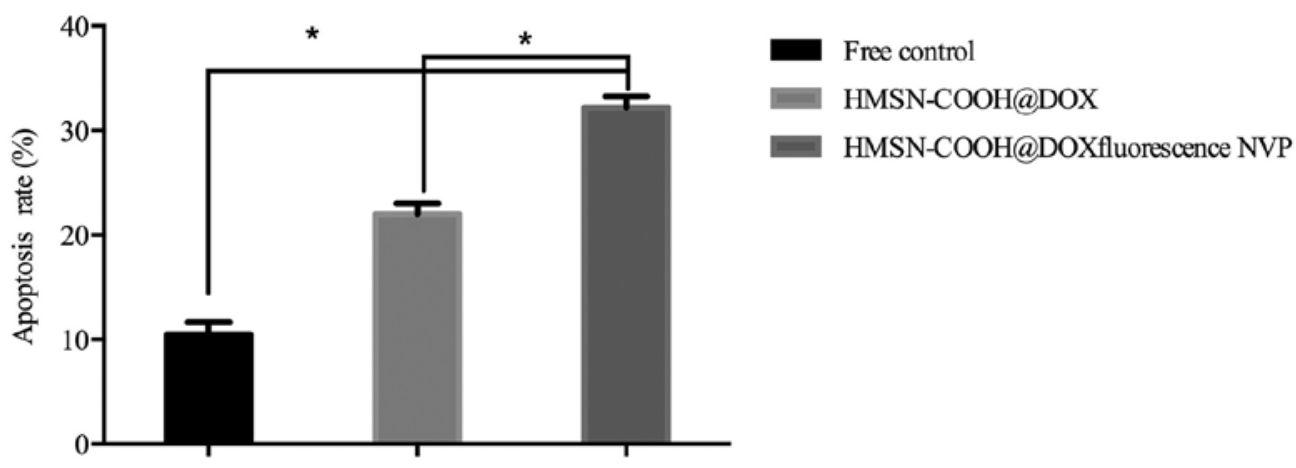

B

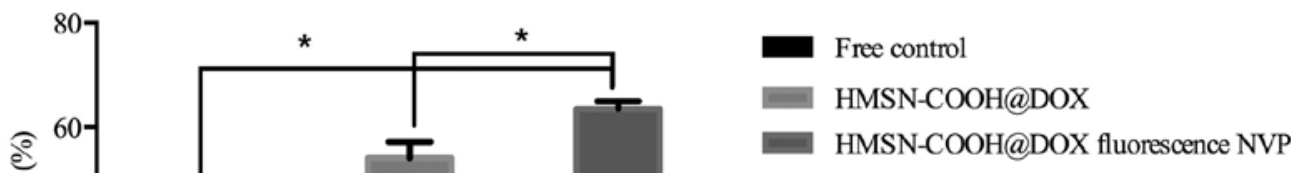

$\mathrm{C}$
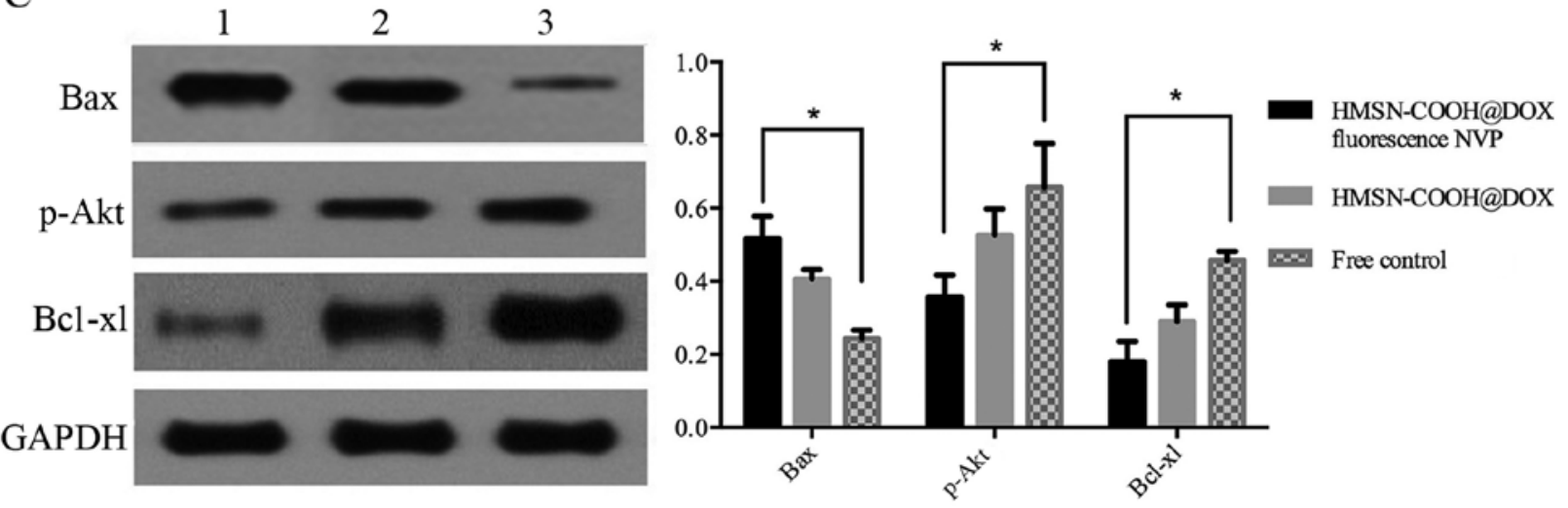

Figure 7. In vitro effect of the co-delivery system. In the HMSN-COOH@ fluorescence NVPDOX group, cell apoptosis rate (A) and inhibition rate (B) were both increased significantly; the expression of protein Bax was significantly increased [(C) 1, HMSN@DOX fluorescence NVP group; 2, HMSN@DOX group; 3 , free control], while the expression of Bcl-xl and p-Akt were decreased.

IGF-1 is a multifunctional regulatory factor extensively involved in various cell functions. Activation of IGF-1 pathway induces DNA synthesis and mitosis through promotion of G2/M transition. Numerous studies showed that the IGF signal axis is involved in malignant transformation and exerts an antiapoptotic effect (16). In this study, we chose the IGF-1 as the therapy target of HMSN@DOX fluorescence NVP co-delivery system to build and investigate the in vitro effect of this system in a tumor stem-like cell line.

Targeting accumulation of nanocarriers is the basis of the co-delivery system. With nanocarriers the size of $\sim 100 \mathrm{~nm}$ is easier to achieve EPR effect, and the smaller the nanocarriers are, the less likely they are to be recognized and deprived by macrophages, the longer their retention time in the bloodstream (17-20). The HMSN synthesized in our laboratory with a size of $50 \mathrm{~nm}$ can not only achieve EPR effect, but also reduce the probability of phagocytosis and achieve the enrichment in tumor tissue.
However, depending on the classification and differentiation of tumor tissue, EPR effect may vary significantly and actively targeting methods are still required. NVP was used as the active targeting group because of the specific binding with IGF-1R. In this system, the low $\mathrm{pH}$ value in tumor tissues caused by anaerobic glycolysis was used as $\mathrm{pH}$-sensitive switch to achieve the targeted drug release (21). The HMSN system enters into the tumor cells via a non-specific endocytosis, then the carboxyl group on the surface will be protonated, leading to a change from electrostatic attraction between the loaded drugs and HMSN into a repulsion mode, which results in drug release. According to this mechanism, drug loaded in the HMSN is minimally released in the circulatory system, which effectively reduces the systemic side effects of chemotherapy drugs. In addition, in contrast to the conventional chemotherapy regimens, HMSN drug delivery system can avoid the recognition of $\mathrm{ABC}$ superfamily, which can pump out the free drug and lead to multidrug resistance $(22,23)$. 
Tumor stem cells can exists in body for a long time in the stationary state, which may be associated with immune escape (11). The significantly higher apoptosis rate in NVP inhibiting group showed that blockade of IGF-1 can inhibit the proliferation and promote apoptosis of ovarian cancer stem-like cells. From this point of view, IGF-1R can be used as a target for the prevention of tumor recurrence. The phosphorylation of IGF-1R activates multiple pathways including the PI3K-AKT signaling cascade, which upregulates the expression of cyclin B1 (24). Cyclin B1 promotes the G2/M transition, and associated with tumor invasion and tumor malignant degree $(25,26)$.

The in vitro experiment was carried out to compare the efficiency of the co-delivery system and free drugs. Significantly higher cell apoptosis and more inhibition of cell proliferation were observed in the co-delivery system. The level of phosphorylated aspartic acid specificity cysteine protease AKT, apoptosis-promoting protein Bax and apoptosis-inhibiting protein Bcl-xl were mostly affected following cell treatment with the co-delivery system. Thus, compared with HMSN-COOH@DOX, the enhanced cell apoptosis by HMSN-COOH@DOX fluorescence NVP is associated with the active targeting as well as blocking effect on IGF-1 by NVP. These results indicated the HMSN-COOH@DOX fluorescence NVP co-delivery system can achieve more potent antitumor effect on ovarian cancer stem cells than conventional regimens $(27,28)$.

In conlusion, we constructed a HMSN-COOH@DOX fluorescence NVP co-delivery module and preliminarily verified the potential efficacy of the system in a stem-like ovarian cancer cell line. Through accumulation effect, intracellular release and delayed efflux, stronger antitumor effect could be achieved by this system. In addition, as doxorubicin mainly release inside tumor tissue and reduces the drug amount in the circulation theoretically, the effective dose of doxorubicin packaged in the HMSN co-delivery system may be far below the current clinical dosage, thus relieving the accumulated toxicity of doxorubicin. However, the above needs to be verified in vivo experiments, which are under investigation in our laboratory.

However, there are still some deficiencies. More research should be carried out in the future to test and verify the antitumor effect of the co-delivery system in other ovarian cancer cell lines, such as SKOV-3 and HO8910, which also have highly expressed IGF-1 and IGF-1R (29-31). Adverse effects and safety concerns should also be addressed before clinical application of the system.

\section{References}

1. Beauchamp MC, Yasmeen A, Knafo A and Gotlieb WH: Targeting insulin and insulin-like growth factor pathways in epithelial ovarian cancer. J Oncol 2010: 257058, 2010.

2. Mantia-Smaldone GM, Corr B and Chu CS: Immunotherapy in ovarian cancer. Hum Vaccin Immunother 8: 1179-1191, 2012

3. Boccardi E, Philippart A, Juhasz-Bortuzzo JA, Beltrán AM, Novajra G, Vitale-Brovarone C, Spiecker E and Boccaccini AR: Uniform surface modification of 3D bioglass (®)-based scaffolds with mesoporous silica particles (MCM-41) for enhancing drug delivery capability. Front Bioeng Biotechnol 3: $177,2015$.

4. Liu J, Luo Z, Zhang J, Luo T, Zhou J, Zhao X and Cai K: Hollow mesoporous silica nanoparticles facilitated drug delivery via cascade $\mathrm{pH}$ stimuli in tumor microenvironment for tumor therapy. Biomaterials 83: 51-65, 2016.
5. Li N, Huang C, Luan Y, Song A, Song Y and Garg S: Active targeting co-delivery system based on $\mathrm{pH}$-sensitive methoxypoly (ethylene glycol) $2 \mathrm{~K}$-poly ( $\varepsilon$-caprolactone)4K-poly (glutamic acid) $1 \mathrm{~K}$ for enhanced cancer therapy. J Colloid Interface Sci 472: 90-98, 2016.

6. Huang Y, Jiang Y, Wang H, Wang J, Shin MC, Byun Y, He H, Liang Y and Yang VC: Curb challenges of the 'Trojan Horse' approach: Smart strategies in achieving effective yet safe cellpenetrating peptide-based drug delivery. Adv Drug Deliv Rev 65: 1299-1315, 2013.

7. Han L, Tang C and Yin C: Dual-targeting and $\mathrm{pH} /$ redoxresponsive multi-layered nanocomplexes for smart co-delivery of doxorubicin and siRNA. Biomaterials 60: 42-52, 2015.

8. Bowker SL, Majumdar SR, Veugelers P and Johnson JA: Increased cancer-related mortality for patients with type 2 diabetes who use sulfonylureas or insulin: Response to Farooki and Schneider. Diabetes Care 29: 1990-1991, 2006.

9. Brokaw J, Katsaros D, Wiley A, Lu L, Su D, Sochirca O, de la Longrais IA, Mayne S, Risch H and Yu H: IGF-I in epithelial ovarian cancer and its role in disease progression. Growth Factors 25: 346-354, 2007.

10. Attias-Geva Z, Bentov I, Fishman A, Werner H and Bruchim I: Insulin-like growth factor-I receptor inhibition by specific tyrosine kinase inhibitor NVP-AEW541 in endometrioid and serous papillary endometrial cancer cell lines. Gynecol Oncol 121: 383-389, 2011.

11. Zhan Q, Wang C and Ngai S: Ovarian cancer stem cells: A new target for cancer therapy. BioMed Res Int 2013: 916819, 2013.

12. Burgos-Ojeda D, Rueda BR and Buckanovich RJ: Ovarian cancer stem cell markers: Prognostic and therapeutic implications. Cancer Lett 322: 1-7, 2012.

13. Kryczek I, Zou L, Rodriguez P, Zhu G, Wei S, Mottram P, Brumlik M, Cheng P, Curiel T, Myers L, et al: B7-H4 expression identifies a novel suppressive macrophage population in human ovarian carcinoma. J Exp Med 203: 871-881, 2006.

14. Curiel TJ, Coukos G, Zou L, Alvarez X, Cheng P, Mottram P, Evdemon-Hogan M, Conejo-Garcia JR, Zhang L, Burow M, et al: Specific recruitment of regulatory $T$ cells in ovarian carcinoma fosters immune privilege and predicts reduced survival. Nat Med 10: 942-949, 2004.

15. Trinchero A, Bonora S, Tinti A and Fini G: Spectroscopic behavior of copper complexes of nonsteroidal anti-inflammatory drugs. Biopolymers 74: 120-124, 2004.

16. Gallagher EJ and LeRoith D: The proliferating role of insulin and insulin-like growth factors in cancer. Trends Endocrinol Metab 21: 610-618, 2010.

17. Jun YW, Lee JH and Cheon J: Chemical design of nanoparticle probes for high-performance magnetic resonance imaging. Angew Chem Int Ed Engl 47: 5122-5135, 2008.

18. Peer D, Karp JM, Hong S, Farokhzad OC, Margalit R and Langer R: Nanocarriers as an emerging platform for cancer therapy. Nat Nanotechnol 2: 751-760, 2007.

19. Gullotti E and Yeo Y: Extracellularly activated nanocarriers: A new paradigm of tumor targeted drug delivery. Mol Pharm 6: 1041-1051, 2009.

20. Meng H, Xue M, Xia T, Ji Z, Tarn DY, Zink JI and Nel AE: Use of size and a copolymer design feature to improve the biodistribution and the enhanced permeability and retention effect of doxorubicin-loaded mesoporous silica nanoparticles in a murine xenograft tumor model. ACS Nano 5: 4131-4144, 2011.

21. Liu N, Han J, Zhang X, Yang Y, Liu Y, Wang Y and Wu G: pH-responsive zwitterionic polypeptide as a platform for antitumor drug delivery. Colloids Surf B Biointerfaces 145: 401-409, 2016.

22. Li W, Zhang H, Assaraf YG, Zhao K, Xu X, Xie J, Yang DH and Chen ZS: Overcoming ABC transporter-mediated multidrug resistance: Molecular mechanisms and novel therapeutic drug strategies. Drug Resist Updat 27: 14-29, 2016.

23. Wu Q, Yang Z, Nie Y, Shi Y and Fan D: Multi-drug resistance in cancer chemotherapeutics: Mechanisms and lab approaches. Cancer Lett 347: 159-166, 2014.

24. Whitley BR, Beaulieu LM, Carter JC and Church FC: Phosphatidylinositol 3-kinase/Akt regulates the balance between plasminogen activator inhibitor-1 and urokinase to promote migration of SKOV-3 ovarian cancer cells. Gynecol Oncol 104: 470-479, 2007.

25. Yang B, Zhao Y, Lou C and Zhao H: Eupalinolide O, a novel sesquiterpene lactone from Eupatorium lindleyanum DC., induces cell cycle arrest and apoptosis in human MDA-MB-468 breast cancer cells. Oncol Rep 36: 2807-2813, 2016. 
26. Wang LH, Jiang XR, Chen GL, Guo W, Zhang JY, Cui LJ, Li HH, Li M, Liu X, Yang JY, et al: Anti-tumor activity of SL4 against breast cancer cells: Induction of G2/M arrest through modulation of the MAPK-dependent p21 signaling pathway. Sci Rep 6: 36486, 2016.

27. Subramaniam S and Unsicker K: Extracellular signal-regulated kinase as an inducer of non-apoptotic neuronal death. Neuroscience 138: 1055-1065, 2006.

28. Andersen JL and Kornbluth S: The tangled circuitry of metabolism and apoptosis. Mol Cell 49: 399-410, 2013.

29. Singh RK, Gaikwad SM, Jinager A, Chaudhury S, Maheshwari A and Ray P: IGF-1R inhibition potentiates cytotoxic effects of chemotherapeutic agents in early stages of chemoresistant ovarian cancer cells. Cancer Lett 354: 254-262, 2014.
30. Jia J, Zhang Y, Cai J, Wang J, Ding H, Zhou J, Fang F and Wang Z: A novel function of protein kinase $B$ as an inducer of the mismatch repair gene hPMS2 degradation. Cell Signal 25: 1498-1504, 2013.

31. Rao W, Li H, Song F, Zhang R, Yin Q, Wang Y, Xi Y and Ge H: OVA66 increases cell growth, invasion and survival via regulation of IGF-1R-MAPK signaling in human cancer cells. Carcinogenesis 35: 1573-1581, 2014. 